\title{
Polyomavirus BK and prostate cancer: an unworthy scientific effort?
}

\author{
Serena Delbue ${ }^{1}$, Pasquale Ferrante $^{1, *}$ and Maurizio Provenzano ${ }^{2, *}$ \\ ${ }^{1}$ Department of Biomedical, Surgical and Dental Sciences, University of Milano, Italy \\ ${ }^{2}$ Oncology Unit, Division of Urology, University Hospital of Zurich, Switzerland \\ * These authors contributed equally to this work \\ Correspondence to: Maurizio Provenzano, email: Maurizio.Provenzano@usz.ch \\ Keywords: Polyomavirus BK, BKV-DNA detection, prostate cancer, meta-analysis \\ Received: March 24, 2014 \\ Accepted: April 30, 2014 \\ Published: April 30, 2014
}

This is an open-access article distributed under the terms of the Creative Commons Attribution License, which permits unrestricted use, distribution, and reproduction in any medium, provided the original author and source are credited.

\section{ABSTRACT:}

The Polyomavirus BK (BKV) has been proposed to be one of the possible cofactors in the genesis of prostate cancer (PCa) but, so far, the only convincing suggestion is the hypothesis of a "hit and run" carcinogenic mechanism induced by the virus at early stages of this disease. To support this hypothesis we conducted an updated systematic review on previous studies regarding the association between BKV and $\mathrm{PCa}$, in order to interpret the contrasting results and to explore whether there might be a significant virus-disease link. This updated analysis provides evidence for a significant link between BKV expression and PCa development, particularly between the BKV infection and the cancer risk. Forthcoming scientific efforts that take cue from this study might overcome the atavistic and fruitless debate regarding the BKV-PCa association.

Polyomavirus BK and prostate cancer; an unsolved dilemma

Prostate cancer $(\mathrm{PCa})$ is the third most common cause of morbidity and the fourth leading cause of cancer death in western countries [1], but it is becoming increasingly more relevant worldwide due to higher life expectancy and refinement of diagnostic procedures $[2,3]$. Among other consistent risk factors [4-6], the pathogenesis of this malignancy reflects chronic inflammatory states and the proliferative inflammatory atrophy (PIA) has been postulated to be the key transition step toward overt PCa [7]. Infectious agents have been ranked among inflammatory-related factors that are important for PCa onset [8]. This also includes viruses that presumably play a causative role in PIA development [9]. However, virus involvement in prostate carcinogenesis remains to be demonstrated [10]. Human Polyomavirus $\mathrm{BK}(\mathrm{BKV})$ is a circular double stranded DNA virus that belongs to the Polyomaviridae family [11]. It establishes a life-long persistent asymptomatic infection in the urinary tract latently residing in the urothelium [12]. Both human and cellular immune responses mounted against capsid antigens patrol the viral activity in immumocompetent individuals but the balance between immune defence and viral fitness is mainly due to cellular immune responses when reactivations occur $[13,14]$, particularly at sites of smoldering infections [15]. However, when the immune system is compromised following an ablative therapy before organ transplantation, after HIV associated immunosuppression or pharmacologic immunosuppression, this immune balance is lost and the viral reactivation leads to a productive infection in permissive cells with the release of new virions in the peripheral blood (viremia) and their shedding in the urine (viruria) [16, 17]. The increase in rate and level of BKV replication might lead to severe diseases at the anatomical site of relevance, such as the hemorrhagic cystitis in bladder and/or the polyomavirus-associated nephropathy (PVAN) in kidney, which is the principal cause of the transplant rejection of the organ $[18,19]$. In contrast, the viral entry in non-permissive cells can lead to an oncogenic transformation as a consequence of an abortive infection [20]. 
Although several oncogenic viruses have already been linked to human malignancies [21], such as papillomavirus (HPV) to cervical and anogenital cancer [22], Epstein-Barr virus (EBV) to Burkitt's lymphoma [23] and nasopharyngeal carcinoma [24, 25], the confirmation of the effects of polyomaviruses in the genesis of human cancers, except for Merkel Cell polyomavirus and Merkel Cell carcinoma [26], has proven more difficult. This in turn rendered the acceptance of a causal role of these viruses in the etiology of human cancers much harder. The oncogenic activity of polyomaviruses has been documented in vitro in cell lines [27] and in hamsters [28]. It is exerted through the main regulatory protein L-Tag which binds products of tumor suppressor genes ( $\mathrm{pRb}$ family, p53) thus interfering with the strategic checkpoints of the cell cycle of infected cells [29]. In addition, the $\mathrm{p} 53 / \mathrm{L}$-Tag complex binds and activates the insulin-like growth factor 1 (IGF-1) thus potentiating the cancer transformation of infected cells [30]. Indeed, it has lately been proposed that the main hallmark of the polyomavirus involvement in cancer development might be the presence of the wt-p53/L-Tag complexes in the cytoplasm of transformed cells. This complex appears after the binding of L-Tag to the wt-p53 in the nucleous of infected cells and the sequestration of the suppressor protein in their cytoplasm [31]. This might suggest the ranking of BKV L-Tag among the wider range of tumor inducers as a potential co-factor for PCa development [9]. Despite evidence of DNA detection and expression of viral gene products in pre-cancerous/cancerous lesions of the prostate, discrepancies between polyomavirus BK infection of the organ and the onset of human prostate cancer are still ruling the scientific discussion [32]. Is this investigation thus worth the efforts if there might not be any solid scientific ground?

A

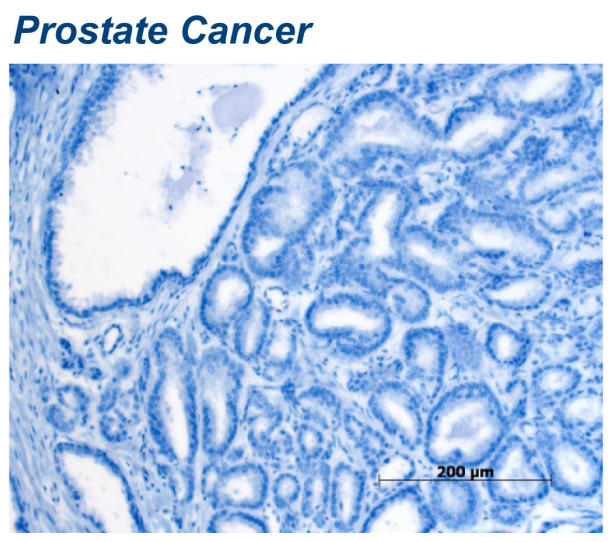

\section{A narrow borderline between BKV behavior as a co-factor or bystander: the "hit and run" hypothesis}

Plenty of work is required to discover the molecular mechanism underlying the viral oncogenic activity [33] and to understand how oncogenic viruses interfere with and orchestrate the tumor microenvironment $[34,35]$. The "hit and run hypothesis" is the most valid proposition to justify a co-factorial role of BKV in PCa onset and progression [9]. It has been introduced by Skinner in 1976 [36] and re-proposed by Galloway in 1983 [37] to stress the oncogenic potential of human herpes viruses (HSV) in cervical cancer and recently by Stevenson to provide experimental support [38]. The hypothesis also helps to explain the disparity between the gene expression of BKV L-Tag in prostatic tumor specimens and its rare expression at protein level in same specimens (Fig 1). It thus seems that the ability of polyomavirus to interfere with the cell cycle could induce the infected cells to reach the critical point of no return during oncogenic transformation [39]. Once the cell cycle is manipulated and the sequestration of p53 is accomplished by L-Tag in the context of an abortive infection, accumulation of gene mutations in the infected cells might lead to transformation without a continuous "support" of viral components [40,41]. The activity of the virus paves the way for tumorigenic transformation at early stages of $\mathrm{PCa}$ and the presence of viral fitness in the tumor cells is no longer necessary to charge the tumor causality to the virus itself $[38,42]$. Nonetheless, the "hit and run" theory is hard to be sustained experimentally due to the obvious difficulty in providing evidence for a resolved infection. In overt cancer, it will lead to a drastic reduction of sensitivity for tests detecting viral genes due to the complete disappearance of the virus in tumor cells

B

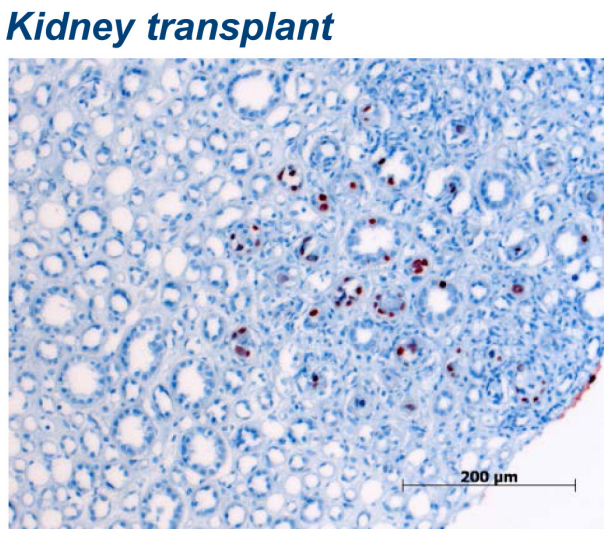

Figure 1: Discrepancies between BKV L-Tag DNA detection and IHC in tumor specimens. A) A representative PCa tissue specimen, among those tested for molecular detection of BKV L-Tag DNA in Sais et al. [57], shows an evident lack of IHC staining for BKV L-Tag, as compared to B) a tissue specimen from a kidney transplant with virus reactivation (unpublished data provided by the authors). 


\section{Table 1: Studies selected for the analysis by a limited Medline. BKV-DNA prevalence in case and control group according to "specimens' adjustment".}

\begin{tabular}{|c|c|c|c|c|c|c|c|c|c|c|c|c|}
\hline \multirow[b]{2}{*}{ Strodiex } & \multirow[b]{2}{*}{$\begin{array}{l}\text { case } \\
\text { tested }\end{array}$} & \multicolumn{4}{|c|}{ Case group } & \multicolumn{7}{|c|}{ Control group } \\
\hline & & $\begin{array}{l}\text { case } \\
\text { positive }\end{array}$ & $\begin{array}{c}\text { prevales co } \\
(0 / 6)\end{array}$ & $\begin{array}{l}\text { as } \theta \\
\text { sfter adj }\end{array}$ & $\begin{array}{l}\text { caso pos } \\
\text { sfrer adj }\end{array}$ & $\begin{array}{c}\text { provalesce } \\
\text { after adj }(\theta, b)\end{array}$ & $\begin{array}{l}\text { control } \\
\text { tes tad }\end{array}$ & $\begin{array}{l}\text { osetrol } \\
\text { posifíce }\end{array}$ & $\begin{array}{c}\text { provalesce } \\
(9,9)\end{array}$ & $\begin{array}{l}\text { cotrol } \\
\text { after adj }\end{array}$ & $\begin{array}{l}\text { contrd pos } \\
\text { sfier adj }\end{array}$ & $\begin{array}{l}\text { provalescs } \\
\text { after adj }(0,6)\end{array}$ \\
\hline Mocin & 7 & 4 & 37,1 & 7 & 4 & 57,1 & 19 & 11 & 379 & 19 & 11 & 57,9 \\
\hline Zambraso & 7 & 2 & 28,6 & 18 & 3 & 16,7 & 11 & 1 & 9,1 & - & - & \\
\hline Des & 21 & 15 & 71,4 & 21 & 15 & 71,4 & - & - & & - & - & \\
\hline Bergh & 171 & 0 & 0,0 & 171 & 0 & 0,0 & 181 & 0 & 0,0 & 181 & 0 & 0,0 \\
\hline Laz & 30 & 2 & 6,7 & 99 & 7 & 7,1 & 69 & 5 & 7.2 & - & $\cdot$ & \\
\hline Sfanos & 113 & 1 & 0,9 & 326 & 1 & 0,3 & 213 & 0 & 0,0 & - & - & \\
\hline Bda & 42 & 8 & 19,0 & 42 & 3 & 19,0 & - & - & & - & - & \\
\hline Des & 14 & 11 & 78,6 & 14 & 11 & 78,6 & 15 & 4 & 26,7 & 15 & 4 & 26,7 \\
\hline R:ess & 26 & 22 & 34,6 & 26 & 22 & 34,6 & 12 & 0 & 0,0 & 12 & 0 & 0,0 \\
\hline Marina-F earo & 55 & 0 & 0,0 & 55 & 0 & 0,0 & 75 & 0 & 0,0 & 75 & 0 & 0,0 \\
\hline 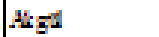 & 35 & 1 & 1,2 & 35 & 1 & 1,2 & - & - & & - & - & \\
\hline Groom & 100 & 0 & 0,0 & 100 & 0 & 0,0 & - & - & & - & - & \\
\hline $3 x$ & 43 & 18 & 41,9 & 43 & 18 & 41,9 & 38 & 12 & 31,6 & 38 & 12 & 31,6 \\
\hline Debos & 328 & 56 & 17,1 & 328 & 56 & 17,1 & 385 & 26 & 6,8 & 385 & 26 & 6.8 \\
\hline Znoog & 64 & 6 & 9,4 & 64 & 6 & 9,4 & 50 & 1 & 2,0 & 50 & 1 & 2,0 \\
\hline TOT & 1105 & 145 & 13.2 & 1399 & 152 & 109 & 1058 & 60 & 5.6 & 775 & 54 & 69 \\
\hline & & & $\% 6 \mathrm{Cl} 11.2 \mathrm{~s}$ & & & $95 \% 6 C I 4.2-7.0$ & & & $5 \% 6 C I$ 9.3-12. & & & $95 \%$ CI 5.1 .8 \\
\hline
\end{tabular}

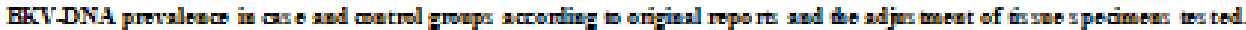

In bold: $x$ todies that we ed fis sees from cascor besing prostats as ootrols

[38]. To support the "hit and run" theory, in the present study we assessed a cumulative prevalence of BKV in PCa. We calculated the risk of cancer development with $\mathrm{BKV}$ infection on previous studies regarding the association between $\mathrm{BKV}$ and $\mathrm{PCa}$ in order to interpret the contrasting results and to explore whether there might be a significant virus-disease link.

\section{BKV-DNA expression in cancer specimens: original reports against specimens' adjustment}

According to new features of early pre-cancerous lesions in their progression to overt PCa [43], we performed an adjustment in the case group including also both non-neoplastic/precancerous and early-stage cancer lesions from cancer bearing prostate, which originally were attributed to the control group. This "specimens' adjustment" allowed us to extend the search for virus expression into lesions at very early stages of $\mathrm{PCa}$ development. Consequently, in the case-control study we considered a "case" each tumor specimen obtained from PCa patients enrolled in each study and a "control" each specimen originating from non PCa patients, such as benign prostatic hyperplasia (BPH) patients or healthy tissues from other patients. We then particularly compared a standard analysis to a specific one by adding the adjustment of tissue samples. With this updated analysis we were aiming at confirming the co-factorial activity of polyomavirus $\mathrm{BK}$ in prostate cancer by categorizing its expression in tumor lesions into marginal, moderate or substantial for risk of PCa development. A limited Medline search for the keywords "BK virus", "prostatic" and "prostate cancer" identified twenty-five papers.
Fifteen out of the twenty-five articles met the criteria by using the molecular-based techniques for the detection of BKV DNA or proteins in tissues. The other ten were excluded for the following reasons: reviews $(n=3)$ [44$46]$, serological studies $(n=3)$ [47-49], case report $(n=1)$ [50], comment $(n=1)$ [51], cell line study $(n=1)$ [52] or publication in language other than English $(n=1)$ [53]. Out of the fifteen articles included in the analysis, eight were carried out in Europe (Italy [54-56], Switzerland [57], UK [58], Sweden [59], Greece [60], Germany [61]), five in USA [9, 31, 62-64], one in Mexico [65] and one in Japan [66]. Due to lack of information if tests were performed considering one specimen as one patient (i.e. multiple tissue collection from each enrolled patient), we included each tumor tissue (case) or normal tissue (control) specimen analyzed for BKV-DNA expression in our statistic. Statistical analysis was performed with MedCalc software (v12.7.7). Estimations (95\% CI) of single prevalence and pooled prevalence were determined by meta-analysis of either original reports or after adding the "specimens' adjustment".

Based on the original reports, a total of 1106 cancers, ranging from 7 to 328 (mean value $=74 ; n=15)$, and 1068 controls, ranging from 11 to 385 (mean value $97 ; n=11$ ) were analyzed. The prevalence of BKV was significantly higher in cancer tissues than in the control tissues $(\mathrm{p}<0.0001)$. Indeed, the range was $0 \%$ to $84.6 \%$, with an overall value of $13.2 \%$ (95\% CI: $11.2 \%-15.9 \%)$ in cancers, and $0 \%$ to $57.9 \%$ with an overall value of $5.6 \%$ (95\% CI: 4.2\%-7.0\%) in controls (Table 1). Three groups collected as control specimens non neoplastic prostate tissues from areas surrounding cancer lesions, such as inflammatory/atrophic specimens adjacent to or 
Table 2: BKV-DNA prevalence in PCa according to techniques used and types of specimen tested with and without adjustment.

\begin{tabular}{|c|c|c|c|c|c|c|c|}
\hline Categories & No ${ }^{\circ}$ of studies & $\begin{array}{l}\mathrm{No}^{\circ} \text { of } \\
\text { tissues }\end{array}$ & $\begin{array}{c}\text { Prevalence } \\
(\%)\end{array}$ & $95 \% \mathrm{CI}$ & $\begin{array}{c}\mathrm{No}^{\circ} \text { of } \\
\text { tissues } \\
\text { after } \\
\text { adjustment }\end{array}$ & $\begin{array}{l}\text { Prevalence } \\
\text { (\%) after } \\
\text { adjustment }\end{array}$ & $95 \% \mathrm{CI}$ \\
\hline Total & 15 & 1106 & 13.2 & $11.2-15.9$ & 1399 & 10.8 & $9.3-12.9$ \\
\hline Technique (total) & 14 & 1076 & & & 1300 & & \\
\hline PCR/nested PCR & 10 & 594 & 7.9 & $5.2-9.0$ & 818 & 6.0 & $4.5-7.5$ \\
\hline qRT-PCR & 4 & 482 & 20.1 & $16.5-23.7$ & 482 & 20.1 & $16.5-23.7$ \\
\hline Type of specimen (total) & 13 & 1057 & & & 1350 & & \\
\hline Paraffin-embedded tissue & 8 & 490 & 14.1 & $16.3-22.5$ & 559 & 13.2 & $10.4-16.0$ \\
\hline Fresh tissue & 5 & 576 & 11.5 & $8.8-14.0$ & 791 & 8.3 & $6.4-10.2$ \\
\hline
\end{tabular}

in transition to prostate adenocarcinoma and early-stage cancer lesions, such as high-grade (HG)-PIN [62-64]. To perform the adjustment, we included these specimens in the case group (1106 cancers) thereby increasing the total number of cases to 1399 (range 7-328, mean $=93.3 ; n=15$ ) while the number of controls decreased to 775 (range 12385 , mean $=96.9 ; \mathrm{n}=8$ ) after adjustment. The prevalence values varied from $0 \%$ to $84.6 \%$, with an overall value of $10.8 \%$ (95\% CI 9.3\%-12.9\%) among cases and from $0 \%$ to $57.9 \%$ with an overall value of $6.9 \%$ (95\% CI $5.1 \%$ $8.7 \%$ ) among the controls (Table 1). Overall, BKV-DNA was detected in about $10 \%$ of prostate tissue specimens tested (206/2174) in $80 \%$ of the studies (12/15) analyzed. Although the prevalence of BKV-DNA detection was obviously reduced in the case group after the adjustment, however not enough to be significant (original $v s$ adjusted analysis $\mathrm{p}=0.08$ ), the modest increase of percentage of BKV-DNA positive lesions in the adjusted group (146 to $152=4 \%$ ) is noteworthy since the significant association between viral expression and cancer observed analyzing the original reports is maintained when including as "cases" all specimens from cancer bearing prostate tested $(\mathrm{p}<0.01)$.

\section{BKV-DNA detection rate among techniques used and types of specimen tested}

The methods for molecular-based testing for BKVDNA detection were: a) the gene assay methods using nested-PCR $(n=9)$, thereof 7 with type-specific primers for L-Tag $(n=6)$ or VP1 $(n=1)$ and 2 with broad spectrum

Monini et al.
Das et al.
Russo et al.
Sais et al.
Delbue et al.
Zhong et al.
Total (fixed effects)
Total (random effects)

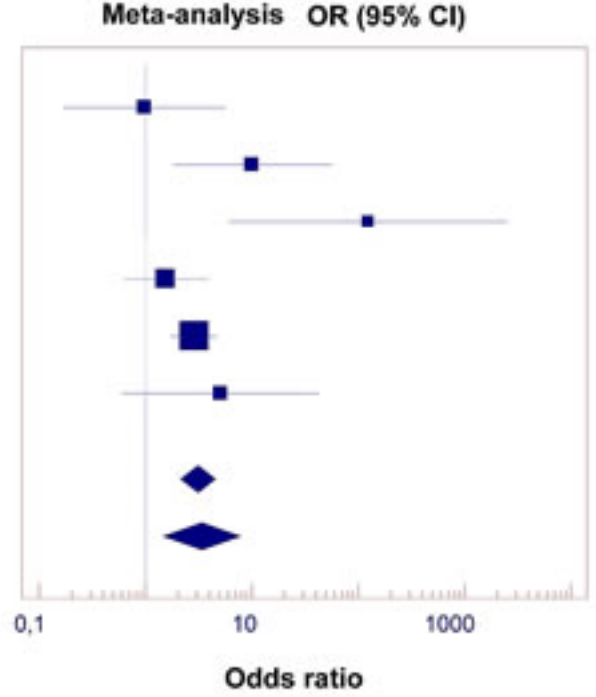

$0.97(0.17-5.59)$

$10.08(1.82-56.0)$

$125.00(6.21-2516.96)$

$1.56(0.63-3.89)$

$2.84(1.74-4.65)$

$1.90(0.23-16.90)$

$3.09(2.11-4.51)$

$3.42(1.48-7.90) \quad l^{2}=57.63 \% ; p=0.038 ; Q=11.8$

Figure 2:Risk of PCa with BKV infection in tumor samples compared with non-tumor prostate samples. The PCa risk with the presence of BKV infection was evaluated by a pooled odds ratio (OR). For measure of inter-study heterogeneity, we used the Cochran's Q test. Fixed effects (Mantel-Haenszel) and random effects (DerSimonian and Laird) models were performed based on the percentage of variation across studies ( $\mathrm{I}^{2}$ statistic). All $\mathrm{p}$-values $<0.05$ were considered statistically significant. 
primers; b) regular PCR with broad-spectrum primers for BKV and JCV VP1 genes $(n=1)$; c) quantitative real time PCR with specific primers and probe (qRT-PCR; $n=4$ ) targeting either L-Tag or VP1 genes or using a kit without any specification. The detection rate for BKV-DNA in tumor tissues by qRT-PCR $(482 ; 44.8 \%)$ was significantly higher than the rate obtained by both nested and regular PCR (594; 55.2\%) either before $(20.1 \%$; $95 \%$ CI 16.5\%$23.7 \%$ vs $7.9 \%$; 95\% CI 5.2\%-9.0\%, p<0.0001) or after the adjustment (qRT-PCR $n=482 ; 20.1 \%$; 95\% CI 16.5\%$23.7 \%$ vs regular PCR $\mathrm{n}=818 ; 6.0 \%$; 95\% CI 4.5\%-7.5\%, $\mathrm{p}<0.0001$ ) (Table 2).

Two additional laboratory methods were employed to analyze BKV expression in tissue specimens. However, due to the limited number of specimens tested the calculation is reported only for completeness of information (data not shown). The "in situ hybridization" (ISH) assay employing a BKV specific probe was carried out in three studies (cases, $\mathrm{n}=79$ ) $[9,31,62]$, showing a strong prevalence of $26.6 \%$ (95\% CI $11.2 \%-28.2 \%$ ). For the detection of BKV proteins, four groups $[9,31$, $56,62]$ employed immunohistochemistry (IHC) assays (cases, $\mathrm{n}=105$ ). In particular, Das et al [9] used an antiVP1 Antibody (P5G6BKV9VP1) while the other groups identified the L-Tag protein using the antibody pAB416 that cross reacts with SV40 and JCV. BKV proteins were significantly more expressed in tumor tissues $(40 \% ; 95 \%$ CI $30.6 \%-49.4 \%)$ than in normal tissues $(5.6 \%$; $95 \%$ CI $0.12 \%-7.1 \% ; \mathrm{p}<0.0001$ ).

Thirteen out of 15 studies mention the type of specimens analyzed in their "material and methods" section. Thus, five studies used fresh or frozen sections ( $\mathrm{F} / \mathrm{F} \mathrm{n}=576,53.6 \%)$, whereas eight studies used formalin fixed, paraffin embedded tissues (FFPE $n=490 ; 46.4 \%$ ). The efficiency at detecting BKV-DNA in FFPE tissue was equal to frozen sections since the detection of $\mathrm{BKV}$ DNA in FFPE tissue was $14.1 \%$ while in frozen section was $11.4 \%(p=0.23)$. Conversely, the difference was highly significant when comparing FFPE $(\mathrm{n}=559 ; 41.4 \%)$ to frozen sections $(\mathrm{n}=791 ; 58.6 \%)$ after the adjustment (13.2\% vs 8.3\%; $\mathrm{p}=0.003$ ) (Table 2). The adjustment confirmed that qRT-PCR is the best gene assay method for BKV DNA detection in tissues and it supports the use of FFPE tissue specimens for molecular-based testing. The latter is of importance since, in addition to the shortage of prostate cancer tissues owing to increasing new therapeutic approaches, such as active surveillance [67], fresh/frozen specimens are also rarely collected for research purpose, due to their prioritized use for diagnostic purposes and the small dimensions of the tumor at first diagnosis [68].

\section{A link between BKV expression and PCa cancer risk supports future investigations}

Six case-control studies with 482 case tissues from PCa patients and 519 control tissues collected from patients with BPH were statistically compared for the estimation of BKV infection and prostate cancer risk. Two studies were automatically excluded after data pooling $[59,65]$, because of the absence of BKV expression in both cases and controls.

The prevalence of BKV was $16.5 \%$ among the tissues from PCa patients (95\% CI 13.8\%-19.2\%) and $7.0 \%$ among the control tissues from $\mathrm{BPH}$ patients $(95 \%$ CI $5.2 \%-8.8 \% ; \mathrm{p}<0.0001)$. According to the results of inter-study heterogeneity $\left(\mathrm{I}^{2}>50 \%\right)$, the random-effect model was used to evaluate the pooled OR. Overall, there was a significantly increased prostate cancer risk with the presence of BKV infection compared with the $\mathrm{BPH}$ controls $(\mathrm{OR}=3.4,95 \%$ CI: 1.5-7.9, $\mathrm{p}=0.04$; Fig. 1$)$ based on an analysis assuming random models $\left(\mathrm{I}^{2}=57.6\right.$ $\mathrm{Q}=11.8)$. Adding studies $(\mathrm{n}=3)$ using pre-cancerous and early-stage cancer tissues as paired controls (case $\mathrm{n}=632$, controls $\mathrm{n}=812$ ), an overall prostate cancer risk with the presence of BKV infection ( $\mathrm{OR}=2.94,95 \% \mathrm{CI}$ 1.51-5.73, $\mathrm{p}=0.09$ ) was marginally maintained assuming random models $\left(\mathrm{I}^{2}=63.4 \mathrm{Q}=13.7\right)$. Obviously, the casecontrol analysis after the specimens' adjustment was not performed due to the lack of control tissues from the three added studies. It is noteworthy that our analysis of the case-control study showed a significantly increased risk for PCa development only when the non-malignant control group consisted of BPH patients, while adding studies that used non neoplastic prostate tissues from PCa bearing patients as control reduced the risk of PCa development to a no longer significant value. This confirms that nonneoplastic prostate tissues adjacent to cancer lesions or cancer-surrounding areas cannot be considered genuine controls, thus justifying the use of specimens' adjustment in this analysis and future investigations.

This link might contribute greatly to clarifying the role of BKV in cancer, and raise the awareness that the virus plays a co-factorial role rather than just being a mere bystander in the development of the tumor.

\section{CONCLUSION}

Prostate cancer is the most common malignancy affecting males and a clinically heterogeneous disease characterized by a variety of histological conditions that render the selection of pure prostatic adenocarcinoma from surrounding non neoplastic areas a difficult task [69]. In some studies used for this meta-analysis, the majority of positive results originated from diagnostic tests performed in inflammatory areas surrounding the cancer and/or atrophic areas at transition zones. In particular, 
inflammation is responsible for either predisposing the prostate to malignant transformation by carcinogens or for initiating and promoting cancer generation by itself [43, 70]. It has been postulated that BKV might be involved in the etiology of main precursor stages of prostate cancer, such as PIA, in areas where histological transitions between inflammation and cancer occur [9, 43]. Therefore, the search of BKV expression at very early stages of neoplastic progression, such as at PIA or PIN levels, is of crucial importance and adjacent tissue surrounding tumor areas or atrophic regions cannot be considered normal controls per se [71].

Our investigation differs from previous analyses in two important aspects. First it is updated to April 2014 including four papers released in 2012 and 2013 which matched our selection criteria. Three of these recently published papers found a positive correlation between the expression of BKV-DNA in cancer specimens and viral features $[54,57,66]$. Second, we adopted a novel strategy in grouping cases and controls. We particularly noted that the adjustment of tissue sampling by including areas being in contact with the cancer, or tissues picked in same cancer bearing organs, either confirmed or improved the statistical significance or even made it more powerful, but it never worsened the situation.

Our findings are thus consistent with a significant link between the BKV infection and the PCa risk. There is thus ample evidence for a potential co-factorial role of $\mathrm{BKV}$ in PCa. A confirmed association between the detection of BKV in cancer lesions, particularly in prostate cancer, and the malignancy could represent a first-step learning model on the causative role of polyomaviruses in cancer. This investigation is thus not an unworthy scientific effort, but rather deserves to be standardized in some ways. The gaps are mainly due to sampling collection schemes and selection of controls. Despite limited, this study might also induce new investigators to provide with new experimental support to understand the interactions between potential oncogenic viruses and the development of cancers.

\section{ACKNOWLEDGMENTS}

The authors thank Damina Balmer for critical comments and Lukas Bubendorf for the IHC assay.

\section{REFERENCES}

1. Jemal A, Bray F, Center MM, Ferlay J, Ward E, Forman D. Global cancer statistics. CA Cancer J Clin. 2011; 61: 69-90.

2. Hayes JH, Barry MJ. Screening for prostate cancer with the prostate-specific antigen test: A review of current evidence. JAMA. 2014; 311: 1143-1149.

3. Choudhury AD, Eeles R, Freedland SJ, Isaacs WB, Pomerantz MM, Schalken JA, Tammela TL, Visakorpi T.
The role of genetic markers in the management of prostate cancer. Eur Urol. 2012; 62: 577-587.

4. Allott EH, Masko EM, Freedland SJ. Obesity and prostate cancer: Weighing the evidence. Eur Urol. 2013; 63: 800809.

5. Damaschke NA, Yang B, Bhusari S, Svaren JP, Jarrard DF. Epigenetic susceptibility factors for prostate cancer with aging. Prostate. 2013; 73: 1721-1730.

6. Ahmed A, Ali S, Sarkar FH. Advances in androgen receptor targeted therapy for prostate cancer. J Cell Physiol. 2014; 229: 271-276.

7. De Marzo AM, Marchi VL, Epstein JI, Nelson WG. Proliferative inflammatory atrophy of the prostate: Implications for prostatic carcinogenesis. Am J Pathol. 1999; 155: 1985-1992.

8. Sfanos KS, De Marzo AM. Prostate cancer and inflammation: The evidence. Histopathology. 2012; 60: 199-215.

9. Das D, Wojno K, Imperiale MJ. BK virus as a cofactor in the etiology of prostate cancer in its early stages. J Virol. 2008; 82: 2705-2714.

10. Delviks-Frankenberry K, Cingoz O, Coffin JM, Pathak VK. Recombinant origin, contamination, and de-discovery of XMRV. Curr Opin Virol. 2012; 2: 499-507.

11. Johne R, Buck CB, Allander T, Atwood WJ, Garcea RL, Imperiale MJ, Major EO, Ramqvist T, Norkin LC. Taxonomical developments in the family polyomaviridae. Arch Virol. 2011; 156: 1627-1634.

12. Hirsch HH, Steiger J. Polyomavirus BK. Lancet Infect Dis. 2003; 3: 611-623.

13. Comoli P, Hirsch HH, Ginevri F. Cellular immune responses to BK virus. Curr Opin Organ Transplant. 2008; 13: 569-574.

14. Egli A, Infanti L, Dumoulin A, Buser A, Samaridis J, Stebler C, Gosert R, Hirsch HH. Prevalence of polyomavirus BK and JC infection and replication in 400 healthy blood donors. J Infect Dis. 2009; 199: 837-846.

15. Turner DL, Gordon CL, Farber DL. Tissue-resident T cells, in situ immunity and transplantation. Immunol Rev. 2014; 258: 150-166.

16. Comoli P, Azzi A, Maccario R, Basso S, Botti G, Basile G, Fontana I, Labirio M, Cometa A, Poli F, Perfumo F, Locatelli F, Ginevri F. Polyomavirus BK-specific immunity after kidney transplantation. Transplantation. 2004; 78: 1229-1232.

17. Comoli P, Binggeli S, Ginevri F, Hirsch HH. Polyomavirusassociated nephropathy: Update on BK virus-specific immunity. Transpl Infect Dis. 2006; 8: 86-94.

18. Ramos E, Drachenberg CB, Wali R, Hirsch HH. The decade of polyomavirus BK-associated nephropathy: State of affairs. Transplantation. 2009; 87: 621-630.

19. Hirsch HH, Knowles W, Dickenmann M, Passweg J, Klimkait T, Mihatsch MJ, Steiger J. Prospective study of polyomavirus type BK replication and nephropathy in 
renal-transplant recipients. N Engl J Med. 2002; 347: 488496.

20. Dalianis T, Hirsch HH. BK polyomavirus and transformation. In Cancer Associated Viruses (Erle S. Robertson Editor). 2012: 419-432.

21. Bergonzini V, Salata C, Calistri A, Parolin C, Palu G. View and review on viral oncology research. Infect Agent Cancer. 2010; 5: 11 .

22. McLaughlin-Drubin ME, Meyers J, Munger K. Cancer associated human papillomaviruses. Curr Opin Virol. 2012; 2: 459-466.

23. Magrath I. Epidemiology: Clues to the pathogenesis of Burkitt lymphoma. Br J Haematol. 2012; 156: 744-756.

24. Chan AT, Lo YM, Zee B, Chan LY, Ma BB, Leung SF, Mo F, Lai M, Ho S, Huang DP, Johnson PJ. Plasma EpsteinBarr virus DNA and residual disease after radiotherapy for undifferentiated nasopharyngeal carcinoma. J Natl Cancer Inst. 2002; 94: 1614-1619.

25. Chan AT, Teo PM, Johnson PJ. Nasopharyngeal carcinoma. Ann Oncol. 2002; 13: 1007-1015.

26. Feng H, Shuda M, Chang Y, Moore PS. Clonal integration of a polyomavirus in human Merkel cell carcinoma. Science. 2008; 319: 1096-1100.

27. Brugge JS, Butel JS. Role of simian virus 40 gene a function in maintenance of transformation. J Virol. 1975; 15: 619635.

28. Cicala C, Pompetti F, Carbone M. SV40 induces mesotheliomas in hamsters. Am J Pathol. 1993; 142: 15241533.

29. Topalis D, Andrei G, Snoeck R. The large tumor antigen: A "swiss army knife" protein possessing the functions required for the polyomavirus life cycle. Antiviral Res. 2013; 97: 122-136.

30. Bocchetta M, Eliasz S, De Marco MA, Rudzinski J, Zhang L, Carbone M. The SV40 large T antigen-p53 complexes bind and activate the insulin-like growth factor-I promoter stimulating cell growth. Cancer Res. 2008; 68: 1022-1029.

31. Das D, Shah RB, Imperiale MJ. Detection and expression of human BK virus sequences in neoplastic prostate tissues. Oncogene. 2004; 23: 7031-7046.

32. Abend JR, Jiang M, Imperiale MJ. BK virus and human cancer: Innocent until proven guilty. Semin Cancer Biol. 2009; 19: 252-260.

33. Dayaram T, Marriott SJ. Effect of transforming viruses on molecular mechanisms associated with cancer. J Cell Physiol. 2008; 216: 309-314.

34. Cader FZ, Vockerodt M, Bose S, Nagy E, Brundler MA, Kearns P, Murray PG. The EBV oncogene LMP1 protects lymphoma cells from cell death through the collagenmediated activation of DDR1. Blood. 2013; 122: 4237 4245.

35. Ren $\mathrm{C}$, Cheng $\mathrm{X}$, Lu B, Yang G. Activation of interleukin-6/signal transducer and activator of transcription 3 by human papillomavirus early proteins 6 induces fibroblast senescence to promote cervical tumourigenesis through autocrine and paracrine pathways in tumour microenvironment. Eur J Cancer. 2013; 49: 3889-3899.

36. Skinner GR. Transformation of primary hamster embryo fibroblasts by type 2 simplex virus: Evidence for a "hit and run" mechanism. Br J Exp Pathol. 1976; 57: 361-376.

37. Galloway DA, McDougall JK. The oncogenic potential of herpes simplex viruses: Evidence for a 'hit-and-run' mechanism. Nature. 1983; 302: 21-24.

38. Stevenson PG, May JS, Connor V, Efstathiou S. Vaccination against a hit-and-run viral cancer. J Gen Virol. 2010; 91: 2176-2185.

39. Dickmanns A, Zeitvogel A, Simmersbach F, Weber R, Arthur AK, Dehde S, Wildeman AG, Fanning E. The kinetics of simian virus 40-induced progression of quiescent cells into $\mathrm{S}$ phase depend on four independent functions of large T antigen. J Virol. 1994; 68: 5496-5508.

40. Gjoerup O, Chang Y. Update on human polyomaviruses and cancer. Adv Cancer Res. 2010; 106: 1-51.

41. Pleasance ED, Cheetham RK, Stephens PJ, McBride DJ, Humphray SJ, Greenman CD, Varela I, Lin ML, Ordonez GR, Bignell GR, Ye K, Alipaz J, Bauer MJ, Beare D, Butler A, Carter RJ, et al. A comprehensive catalogue of somatic mutations from a human cancer genome. Nature. 2010; 463: 191-196.

42. Nevels M, Tauber B, Spruss T, Wolf H, Dobner T. "Hitand-run" transformation by adenovirus oncogenes. J Virol. 2001; 75: 3089-3094.

43. De Marzo AM, Platz EA, Sutcliffe S, Xu J, Gronberg H, Drake CG, Nakai Y, Isaacs WB, Nelson WG. Inflammation in prostate carcinogenesis. Nat Rev Cancer. 2007; 7: 256269.

44. Hrbacek J, Urban M, Hamsikova E, Tachezy R, Heracek J. Thirty years of research on infection and prostate cancer: No conclusive evidence for a link. A systematic review. Urol Oncol. 2013; 31: 951-965.

45. Siguier M, Sellier P, Bergmann JF. BK-virus infections: A literature review. Med Mal Infect. 2012; 42: 181-187.

46. Weinreb DB, Desman GT, Amolat-Apiado MJ, Burstein DE, Godbold JH, Jr., Johnson EM. Polyoma virus infection is a prominent risk factor for bladder carcinoma in immunocompetent individuals. Diagn Cytopathol. 2006; 34: 201-203.

47. Newton R, Ribeiro T, Alvarez E, Ziegler J, Casabonne D, Carpenter L, Beral V, Mbidde E, Parkin DM, Wabinga H, Mbulaiteye S, Jaffe H, Touze A, Coursaget P. BK virus and cancer in Uganda. Eur J Cancer Prev. 2006; 15: 285-289.

48. Newton R, Ribeiro T, Casabonne D, Alvarez E, Touze A, Key T, Coursaget P. Antibody levels against BK virus and prostate, kidney and bladder cancers in the EPIC-Oxford cohort. Br J Cancer. 2005; 93: 1305-1306.

49. Shah KV, Daniel RW, Stone KR, Elliott AY. Investigation of human urogenital tract tumors of papovavirus etiology: Brief communication. J Natl Cancer Inst. 1978; 60: 579- 
582.

50. Fioriti D, Russo G, Mischitelli M, Anzivino E, Bellizzi A, Di Monaco F, Di Silverio F, Giordano A, Chiarini F, Pietropaolo V. A case of human polyomavirus BK infection in a patient affected by late stage prostate cancer: Could viral infection be correlated with cancer progression? Int J Immunopathol Pharmacol. 2007; 20: 405-411.

51. Weinreb DB. BK virus and carcinoma of the prostate, kidney and bladder. Br J Cancer. 2006; 94: 1948; author reply 1949-1950.

52. Wold WS, Mackey JK, Brackmann KH, Takemori N, Rigden P, Green M. Analysis of human tumors and human malignant cell lines for BK virus-specific DNA sequences. Proc Natl Acad Sci U S A. 1978; 75: 454-458.

53. May M, Kalisch R, Hoschke B, Juretzek T, Wagenlehner F, Brookman-Amissah S, Spivak I, Braun KP, Bar W, Helke C. [detection of papillomavirus DNA in the prostate: A virus with underestimated clinical relevance?]. Urologe A. 2008; 47: 846-852.

54. Delbue S, Matei DV, Carloni C, Pecchenini V, Carluccio S, Villani S, Tringali V, Brescia A, Ferrante P. Evidence supporting the association of polyomavirus BK genome with prostate cancer. Med Microbiol Immunol. 2013; 202: 425-430.

55. Monini P, Rotola A, Di Luca D, De Lellis L, Chiari E, Corallini A, Cassai E. DNA rearrangements impairing BK virus productive infection in urinary tract tumors. Virology. 1995; 214: 273-279.

56. Russo G, Anzivino E, Fioriti D, Mischitelli M, Bellizzi A, Giordano A, Autran-Gomez A, Di Monaco F, Di Silverio F, Sale P, Di Prospero L, Pietropaolo V. P53 gene mutational rate, gleason score, and $\mathrm{BK}$ virus infection in prostate adenocarcinoma: Is there a correlation? J Med Virol. 2008; 80: 2100-2107.

57. Sais G, Wyler S, Hudolin T, Banzola I, Mengus C, Bubendorf L, Wild PJ, Hirsch HH, Sulser T, Spagnoli GC, Provenzano M. Differential patterns of large tumor antigen-specific immune responsiveness in patients with BK polyomavirus-positive prostate cancer or benign prostatic hyperplasia. J Virol. 2012; 86: 8461-8471.

58. Groom HC, Warren AY, Neal DE, Bishop KN. No evidence for infection of UK prostate cancer patients with XMRV, BK virus, trichomonas vaginalis or human papilloma viruses. PLoS One. 2012; 7: e34221.

59. Bergh J, Marklund I, Gustavsson C, Wiklund F, Gronberg $\mathrm{H}$, Allard A, Alexeyev O, Elgh F. No link between viral findings in the prostate and subsequent cancer development. Br J Cancer. 2007; 96: 137-139.

60. Balis V, Sourvinos G, Soulitzis N, Giannikaki E, Sofras F, Spandidos DA. Prevalence of BK virus and human papillomavirus in human prostate cancer. Int $\mathrm{J}$ Biol Markers. 2007; 22: 245-251.

61. Akgul B, Pfister D, Knuchel R, Heidenreich A, Wieland U, Pfister H. No evidence for a role of xenotropic murine leukaemia virus-related virus and BK virus in prostate cancer of german patients. Med Microbiol Immunol. 2012; 201: 245-248.

62. Lau SK, Lacey SF, Chen YY, Chen WG, Weiss LM. Low frequency of BK virus in prostatic adenocarcinomas. APMIS. 2007; 115: 743-749.

63. Sfanos KS, Sauvageot J, Fedor HL, Dick JD, De Marzo AM, Isaacs WB. A molecular analysis of prokaryotic and viral DNA sequences in prostate tissue from patients with prostate cancer indicates the presence of multiple and diverse microorganisms. Prostate. 2008; 68: 306-320.

64. Zambrano A, Kalantari M, Simoneau A, Jensen JL, Villarreal LP. Detection of human polyomaviruses and papillomaviruses in prostatic tissue reveals the prostate as a habitat for multiple viral infections. Prostate. 2002; 53: 263-276.

65. Martinez-Fierro ML, Leach RJ, Gomez-Guerra LS, GarzaGuajardo R, Johnson-Pais T, Beuten J, Morales-Rodriguez IB, Hernandez-Ordonez MA, Calderon-Cardenas G, OrtizLopez R, Rivas-Estilla AM, Ancer-Rodriguez J, RojasMartinez A. Identification of viral infections in the prostate and evaluation of their association with cancer. BMC Cancer. 2010; 10: 326.

66. Zhong S, Suzuki M, Peng X, Shen ZJ, Wang XJ, Xu TY, Li T, Yogo Y, Homma Y. BK polyomavirus from patients with tissue-derived prostate adenocarcinoma. Future Virology. 2013; 8: 313-320.

67. van den Bergh RC, Ahmed HU, Bangma CH, Cooperberg MR, Villers A, Parker CC. Novel tools to improve patient selection and monitoring on active surveillance for low-risk prostate cancer: A systematic review. Eur Urol. 2014; in press.

68. Schlomm T, Erbersdobler A, Mirlacher M, Sauter G. Molecular staging of prostate cancer in the year 2007. World J Urol. 2007; 25: 19-30.

69. Boyd LK, Mao X, Lu YJ. The complexity of prostate cancer: Genomic alterations and heterogeneity. Nat Rev Urol. 2012; 9: 652-664.

70. De Marzo AM, Nakai Y, Nelson WG. Inflammation, atrophy, and prostate carcinogenesis. Urol Oncol. 2007; 25: 398-400.

71. Grizzle WE, Srivastava S, Manne U. The biology of incipient, pre-invasive or intraepithelial neoplasia. Cancer Biomark. 2010; 9: 21-39. 